\title{
FORTALECIMENTO DOS CONSELHOS ESCOLARES NO CENÁRIO DA GESTÃO DEMOCRÁTICA DA REDE MUNICIPAL DE ENSINO DE SANTA MARIA - RS
}

\author{
FORTALECIMIENTO DE LOS CONSEJOS ESCOLARES EN EL ESCENARIO DE LA \\ GESTIÓN DEMOCRÁTICA DE LA RED MUNICIPAL DE ENSEÑANZA DE SANTA \\ MARÍA - RS
}
STRENGTHENING OF SCHOOL COUNCIL IN THE DEMOCRATIC MANAGEMENT SCENARIO OF THE MUNICIPAL PUBLIC SCHOOLS OF SANTA MARIA - RS

\author{
Cristina Magalhães Foletto MACHADO ${ }^{1}$ \\ Marilene Gabriel DALLA CORTE ${ }^{2}$
}

RESUMO: O artigo é resultante dos estudos realizados no bojo das pesquisas do grupo Gestar/CNPq, e constitui-se uma das produções do curso de mestrado profissional do Programa de Pós-Graduação em Políticas Públicas e Gestão Educacional da Universidade Federal de Santa Maria. Aborda os princípios da gestão democrática a partir da atuação e fortalecimento dos conselhos escolares nas escolas da Rede Municipal de Ensino de Santa Maria/RS. Nesse contexto, esta pesquisa priorizou compreender como se configura a atuação dos conselhos escolares na Rede Municipal de Ensino de Santa Maria/RS, na perspectiva da gestão democrática, no sentido de contribuir com diretrizes para o fortalecimento desses órgãos colegiados. Verificou-se, no decorrer da pesquisa, que o conceito de gestão educacional resulta de uma mudança de postura frente ao trabalho no contexto das instituições. Com os resultados desse estudo, construiu-se diretrizes destinadas à formação para conselheiros escolares das escolas municipais de Santa Maria/RS. Concluiu-se que com a formação dos membros dos conselhos escolares torna-se possível construir e consolidar a identidade da escola, no sentido de constituir-se como uma instituição de natureza democrática, participativa e que valoriza a pluralidade sociocultural.

PALAVRAS-CHAVE: Conselhos escolares. Formação de conselheiros escolares. Políticas públicas. Gestão escolar democrática.

RESUMEM: El artículo es resultado de los estudios realizados en el seno de las encuestas del grupo Gestar / CNPq, y se constituye una de las producciones del curso de maestría profesional del Programa de Postgrado en Políticas Públicas y Gestión Educativa de la Universidad Federal de Santa María. Aborda los principios de la gestión democrática a partir de la actuación y fortalecimiento de los consejos escolares en las escuelas de la Red

1 Universidade Federal de Santa Maria (UFSM), Santa Maria - RS - Brasil. Coordenadora Pedagógica e Professora da Rede Privada de Ensino de Santa Maria. Mestre em Políticas Públicas e Gestão Educacional pelo Programa de Pós-Graduação em Políticas Públicas e Gestão Educacional (PPPG/UFSM). ORCID: https://orcid.org/0000-0001-9694-9912. E-mail: cmfoletto@gmail.com

${ }^{2}$ Universidade Federal de Santa Maria (UFSM), Santa Maria - RS - Brasil. Professora Adjunta do Departamento de Administração Escolar, do Centro de Educação. Coordenadora Substituta do Programa de Pós-Graduação em Políticas Públicas e Gestão Educacional do PPPG/UFSM. Doutora em Educação. ORCID: https://orcid.org/0000-0001-8272-2944. E-mail: marilenedallacorte@gmail.com 
Municipal de Enseñanza de Santa María / RS. En este contexto, esta investigación priorizó comprender cómo se configura la actuación de los consejos escolares en la Red Municipal de Enseñanza de Santa María / RS, en la perspectiva de la gestión democrática, en el sentido de contribuir con directrices para el fortalecimiento de esos órganos colegiados. En el transcurso de la investigación se verificó que el concepto de gestión educativa resulta de un cambio de postura frente al trabajo en el contexto de las instituciones. Con los resultados de este estudio, se construyeron directrices destinadas a la formación para consejeros escolares de las escuelas municipales de Santa Maria / RS. Se concluye que con la formación de los miembros de los consejos escolares se haga posible construir y consolidar la identidad de la escuela, en el sentido de, principalmente, constituirse como una institución de naturaleza democrática, participativa y que valora la pluralidad sociocultural.

PALABRAS CLAVE: Consejos escolares. Formación de consejeros escolares. Políticas públicas. Gestión escolar democrática.

ABSTRACT: The article is a result of the studies realized in the research of the Gestar / $C N P q$ group, and is one of the productions of the professional master's program of the PostGraduate Program in Public Policies and Educational Management of the Federal University of Santa Maria. It approaches the principles of democratic management based on the performance and strengthening of school councils in the Municipal Public Schools of the Santa Maria / RS. In this context, this research prioritized to understand how the work of the school councils in the Municipal Public Schools is configured, in the perspective of democratic management, in order to contribute with guidelines for the strengthening of these collegiate bodies. In the course of the research, was verified that the concept of educational management results from a change of attitude of work in the context of the institutions. It was concluded that with the formation of the members of the school councils it becomes possible to build and consolidate the identity of the school, in the sense of, mainly, to constitute itself as an institution of democratic nature, participatory and that values the sociocultural plurality.

KEYWORDS: School councils. Training of school counselors. Public policy. Democratic school management.

\section{Introdução}

A sociedade em que vivemos se baseia no princípio democrático de direito. Nessa perspectiva, podemos inferir que participar significa, além de outros direitos, fazer parte dela, efetivamente. Colocar em prática esses direitos requer, portanto, exercer a cidadania pautada do princípio democrático da participação do povo e, nessa perspectiva, torna-se indispensável que as tomadas de decisões sejam uma constância a todo cidadão, outorgados os direitos fundamentais.

De acordo com Bobbio (2004, p. 1):

Direitos do homem, democracia e paz são três momentos necessários do mesmo movimento histórico: sem direitos do homem reconhecidos e 
protegidos, não há democracia, não existem as condições mínimas para a solução pacífica dos conflitos. Em outras palavras, a democracia é a sociedade dos cidadãos, e os súditos se tornam cidadãos quando lhe são reconhecidos alguns direitos fundamentais.

No decorrer da história da humanidade, verificamos que as tentativas de inserção da população nas tomadas de decisões sempre foram muito difíceis, acompanhadas de muitas lutas, resistência, intolerância e centralização do poder. Muitas pessoas que se envolveram em movimentos sociais em favor da participação e democratização pagaram preços altos pela luta por uma autonomia mínima ou mais efetiva nos espaços decisórios ou para a ampliação do direito de "voz" em prol de processos compartilhados e participativos.

Mas, a expressão da autonomia, no seio da gestão democrática escolar, denota a busca pelo espaço participativo no sistema de ensino, em especial, no cenário das instituições escolares. Desde o advento da Lei de Diretrizes e Bases da Educação de 1996, Lei no 9.394, a gestão democrática normatizou-se e tem demonstrado que os caminhos são possíveis às mudanças necessárias ao fortalecimento do processo de emancipação da gestão da educação em todos os níveis e sistemas de ensino. A educação, por meio das suas instituições de ensino, tem um importante papel na construção e ampliação da democratização, na medida em que executa ações de forma responsável e comprometida, debatendo as necessidades contextuais em que elas acontecem e com os interessados que a integram, sugerindo, acompanhando, executando e avaliando compartilhadamente os fins, os meios e os resultados desse processo.

É importante afirmarmos que, nessa perspectiva de ação, "participar" significa tornarse responsável por todas as instâncias do processo - das ideias à execução, acompanhamento, fiscalização, assim como de avaliação das ações e seu possível e necessário redimensionamento. Ou seja, torna-se um compromisso coletivo, pensando em um espaço de bem-estar comum e concretização de objetivos voltados aos interesses comuns da comunidade escolar.

Para tanto, a gestão da educação de caráter democrático implica a organização de um conjunto de mecanismos formais com ações efetivas - que vão desde a legislação, representação, instrumentalização e descentralização de sistemas/instituições/setores e, em especial, a criação de órgãos colegiados, que no caso das escolas são os conselhos escolares, à participação efetiva dos agentes envolvidos, respectivamente.

O conselho escolar (CE) se constituiu, desde a década de 90, um segmento representativo na e da gestão escolar, responsável pelo estudo e planejamento, debate e deliberação, acompanhamento, controle e avaliação das ações, tanto no campo pedagógico (articulando as ações, acompanhando os alunos em relação ao seu rendimento escolar), quanto 
no administrativo e financeiro (direcionando o gasto das verbas de modo a garantir a melhor aplicabilidade desses recursos). Erroneamente, muitas pessoas pensam que o CE serve apenas para fiscalizar ou conduzir a aplicabilidade dos recursos que chegam à escola, o que justifica a pesquisa realizada no cenário do curso de mestrado profissional em políticas públicas e gestão educacional, bem como a necessidade de que os conselheiros escolares tenham compreensão do seu papel junto aos sistemas/redes e instituições de ensino que se encontram num contexto normatizado por princípios democráticos.

Assim sendo, objetivou-se compreender a gestão democrática escolar considerando a atuação dos conselhos escolares na Rede Municipal de Ensino de Santa Maria/RS, no sentido de contribuir com diretrizes para a formação e atuação qualificada dos conselheiros deste órgão colegiado.

Os principais fundamentos teóricos e o percurso metodológico adotados na pesquisa estão delineados a seguir (Figura 1):

Figura 1 - Matriz metodológica da pesquisa

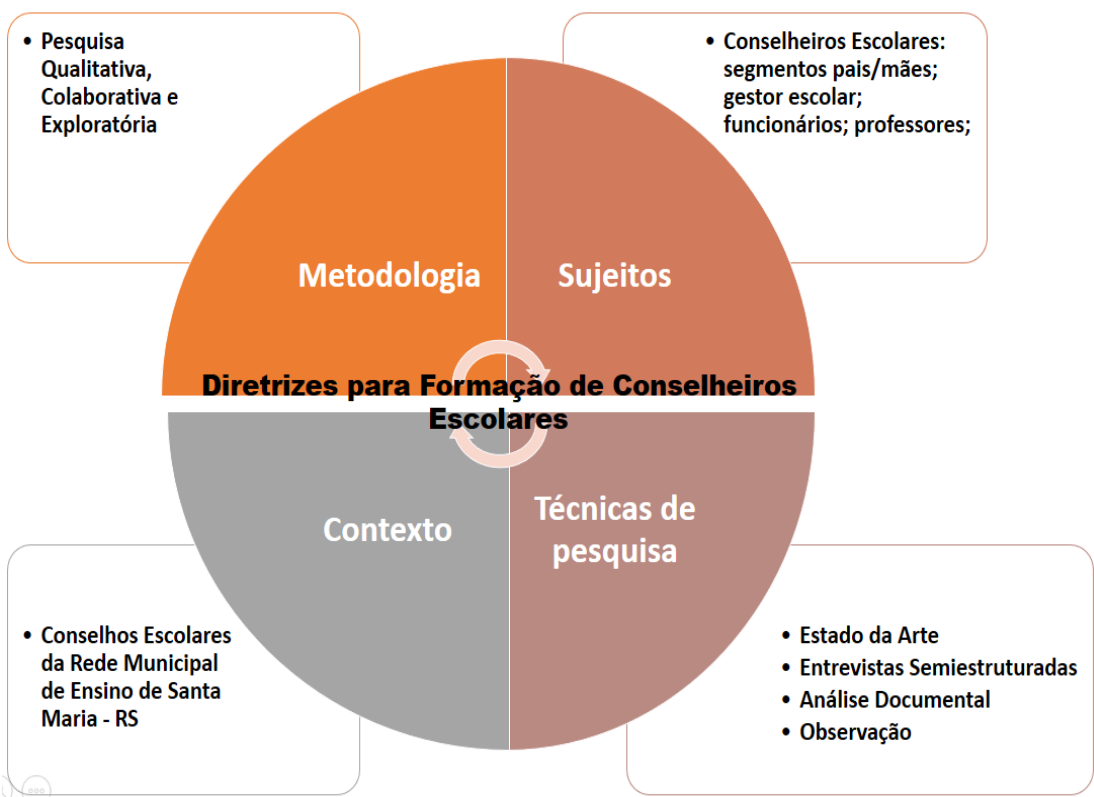

Fonte: Elaborada pela autora.

Os aportes teórico-metodológicos delineados para a pesquisa de natureza qualitativa (FLICK, 2009) encaminharam um percurso de investigação que se constituiu no pressuposto de que a postura de pesquisadora exige constante vigilância sob a perspectiva de que há informações, concepções e práticas a serem investigadas e analisadas com base nas demandas e conjunturas da gestão educacional, em inter-relação com a atuação da gestão escolar na 
perspectiva democrática. Para tanto, partiu-se do pressuposto de que os seres humanos produzem diversos tipos de conhecimento, que são representações da realidade em um determinado momento histórico.

Para Flick (2009), a abordagem qualitativa contém características específicas, entre elas: a realidade como construção e atribuição social de significados; a ênfase ao caráter processual e reflexivo; as condições objetivas de vida que se tornam relevantes por meio de significados subjetivos; o caráter comunicativo da realidade social permite que o refazer do processo de construção das realidades sociais se tornem ponto de partida da pesquisa. Nesse sentido, a pesquisa qualitativa “[...] utiliza o texto como material empírico, parte da noção da construção social das realidades em estudo, está interessada nas perspectivas dos participantes, em suas práticas do dia a dia e em seu conhecimento cotidiano em relação ao estudo". (FLICK, 2009, p. 16).

A natureza qualitativa, como referencial de pesquisa, esteve fundamentada na metodologia de pesquisa colaborativa, justamente porque atende a necessidade de estreitar laços entre contexto e sujeitos, promovendo resultados profícuos relacionados diretamente às práticas sociais, neste caso, desencadeando a “[...] elaboração de novas compreensões acerca dos trabalhos realizados na instituição escolar, estabelecendo um compromisso da academia de também se engajar na busca das soluções para as problemáticas aí apresentadas" (HORIKAWA, 2008, p. 27). Como discute Horikawa (2008), o trabalho colaborativo aponta para a latente necessidade de se construírem discursos cada vez mais polifônicos, em que sejam consideradas as vozes sociais trazidas pelos participantes da organização do trabalho escolar. A autora ressalta, ainda, que no movimento entre teoria e prática há sempre a mediação do sujeito e do contexto, os quais não podem ser desconsiderados. São limites, intenções, possibilidades que permeiam toda a ação dos conselhos escolares, contribuindo para que haja transposição da teoria para a prática (HORIKAWA, 2008).

Ao pontuar a pertinência dessa pesquisa no ambiente escolar, buscou-se em Ibiapina (2008, p. 114) que:

[...] quando o pesquisador aproxima suas preocupações das preocupações dos sujeitos, compreendendo-as por meio da reflexividade crítica, e proporciona condições para que estes revejam conceitos e práticas; e de outro lado, contempla o campo da prática, quando o pesquisador solicita a colaboração dos docentes para investigar certo objeto de pesquisa, investigando e fazendo avançar a formação docente, esse é um dos desafios colaborativos, responder às necessidades de docentes e os interesses de produção de conhecimentos. A pesquisa colaborativa, portanto, reconcilia duas dimensões da pesquisa em educação, a produção de saberes e a formação continuada de professores. Essa dupla dimensão privilegia 
pesquisa e formação, fazendo avançar os conhecimentos produzidos na academia e na escola.

Nesse sentido, priorizou-se buscar a compreensão da realidade e construir novas diretrizes no âmbito da formação com o objetivo de qualificar a atuação dos conselheiros escolares. Assim, investir na formação dos conselheiros com a proposta de fortalecimento da participação legitimada pela gestão democrática, bem como proporcionar a produção de novos conhecimentos, aproximando-os do entendimento da engrenagem que envolve a constituição da escola pública e o conselho escolar, tornou-se prioridade nesse estudo.

Destarte, a pesquisa dividiu-se em etapas que foram articuladas e desenvolvidas com a finalidade de atingir ao objetivo proposto. Inicialmente, realizou-se um amplo levantamento atualizado com relação aos dados e indicadores sociais, políticos, demográficos e educacionais do município de Santa Maria/RS; também aprofundou-se os estudos teóricos referentes aos conceitos norteadores da pesquisa, incluindo a pesquisa do estado da arte; posteriormente, realizou-se a pesquisa de campo colaborativa, com vistas a construir dados referentes à atuação dos conselhos escolares na Rede Municipal de Ensino de Santa Maria/RS, por meio de seus membros constitutivos.

Nesta produção, priorizar-se-á apresentar uma versão panorâmica de resultados da pesquisa que abarcam seus propósitos gerais voltados para a formação dos conselheiros escolares.

\section{Formação dos conselheiros escolares como estratégia de fortalecimento da gestão escolar democrática}

O reconhecimento das reivindicações históricas do movimento dos educadores em prol da gestão democrática, bem como a necessidade de materializá-la no sistema educacional, como preconizado pela LDB/96, constituíram algumas das fortes razões que induziram o Ministério da Educação a inscrever na sua agenda uma política direcionada à ampliação dos espaços de participação nas escolas de educação básica, o que se efetivou mediante a Portaria Ministerial $n^{\circ}$ 2.896/2004, que instituiu o Programa Nacional de Fortalecimento dos Conselhos Escolares.

Este Programa, desenvolvido pela Secretaria de Educação Básica, foi concebido com o propósito de promover a cooperação do MEC com os sistemas estaduais e municipais de ensino, objetivando a implantação, a consolidação e o desempenho dos conselhos escolares nas escolas públicas de educação básica do país. Constituíram, assim, objetivos do Programa: 
I - ampliar a participação das comunidades escolar e local na gestão administrativa, financeira e pedagógica das escolas públicas;

II - apoiar a implantação e o fortalecimento de Conselhos Escolares;

III - instituir políticas de indução para a implantação de Conselhos Escolares;

IV - promover, em parceria com os sistemas de ensino, a capacitação de conselheiros escolares, utilizando inclusive metodologias de educação à distância;

V - estimular a integração entre os Conselhos Escolares;

VI - apoiar os Conselhos Escolares na construção coletiva de um projeto educacional no âmbito da escola, em consonância com o processo de democratização da sociedade;

VII - promover a cultura do monitoramento e avaliação no âmbito das escolas para a garantia da qualidade da educação. (BRASIL, 2004).

Com tais propósitos, o MEC, por meio da Secretaria de Educação Básica (SEB) ${ }^{3}$, envolveu organismos e entidades nacionais e internacionais no processo de formulação dessa política, instituindo um grupo de trabalho interinstitucional com o objetivo de analisar e apresentar propostas que propiciassem o fortalecimento da gestão democrática e dos conselhos escolares nas escolas públicas de educação básica. Integraram esse grupo de trabalho o Conselho Nacional de Secretários de Educação (CONSED); a União Nacional dos Dirigentes Municipais de Educação (UNDIME); a Confederação Nacional dos Trabalhadores em Educação (CNTE); a Organização das Nações Unidas para a Infância (UNICEF); a Organização das Nações Unidas para a Educação, a Ciência e a Cultura (UNESCO) e o Programa das Nações Unidas para o Desenvolvimento (PNUD).

Simultaneamente, a SEB/MEC buscou consultoria de especialistas na área de gestão da educação nas universidades brasileiras para colaborar com a arquitetura e operacionalização do Programa. A SEB privilegiou, entre os objetivos do Programa, a promoção de parcerias com os sistemas de ensino, por intermédio das secretarias estaduais e municipais de educação, como a principal estratégia política, visando, de um lado, alcançar os demais objetivos e, de outro lado, induzir ações que reforçassem o regime de colaboração entre os entes federativos, tal como previsto na Lei de Diretrizes e Bases da Educação Nacional.

Ao atuar dessa forma, o governo federal procurava não só evidenciar uma postura favorável à afirmação do pacto federativo, mas, ao mesmo tempo, dar ampla visibilidade a uma ação político-pedagógica que poderia repercutir de forma positiva nas redes públicas de

\footnotetext{
${ }^{3}$ A Coordenação Geral de Articulação e Fortalecimento Institucional dos Sistemas de Ensino (CAFISE), do Departamento de Articulação e Desenvolvimento dos Sistemas de Ensino (DASE) foi a instância responsável pelo Programa Nacional de Fortalecimento dos Conselhos Escolares.
} 
ensino diretamente envolvidas com esta ação. Porém, esse Programa sequer é conhecido pelos membros dos CE pesquisados.

A análise das dinâmicas referentes à formulação e à implementação do Programa demonstra, sem dúvida, que:

\begin{abstract}
A construção das políticas públicas não é um processo abstrato. Ela é, ao contrário, indissociável da ação dos indivíduos ou dos grupos envolvidos, de sua capacidade de produzir discursos concorrentes, de seus modos de mobilização. Ela depende, também, de estrutura mais ou menos flutuante de suas relações e das estratégias elaboradas nos contextos de ação definidos em especial pelas estruturas institucionais, no interior das quais tomam lugar as políticas públicas. (MULLER; SUREL, 2002, p. 77).
\end{abstract}

Dessa forma, analisar a ação pública exige, portanto, que se leve em consideração os atores e as redes que são tecidas no espaço público. Nesse sentido, entende-se que o Programa favoreceu, no âmbito das redes públicas de ensino, a compreensão de que o conselho escolar deve ser construído de forma coletiva, como um lugar de participação e decisão de caráter pedagógico e político, como um espaço de debate e negociações em torno das necessidades e prioridades da escola e como um canal de democratização da gestão escolar.

Diante disso, diretrizes para a formação qualificada para Conselheiros Escolares subsidia-se na LDB nº 9.394/96 que, no Art. 14, promulga que os sistemas de ensino definirão as normas de gestão democrática do ensino público, e tem seu cumprimento na Lei $\mathrm{n}^{\circ}$ 4.740/2003, a qual instituiu a Gestão Escolar Democrática no município de Santa Maria/RS. Tais processos formativos poderão levar em consideração as demandas e as especificidades levantadas pela pesquisa junto à Rede Municipal de Ensino de Santa Maria. E, ainda, é importante sinalizar o compromisso social dos órgãos públicos para com a comunidade externa.

\title{
Diretrizes para o fortalecimento dos conselhos escolares da Rede Municipal de Ensino de Santa Maria/RS
}

Passados trinta anos da promulgação da Constituição de 1988, a gestão democrática da escola pública, mesmo tendo sido reconhecida como avanço pelos diferentes segmentos da sociedade, ainda não se firmou como uma realidade, demandando como esforço coletivo para a sua efetivação. O termo gestão democrática é consagrado pela primeira vez nesta mesma Constituição, como resultado de luta travada entre segmentos da sociedade civil, nos âmbitos público e privado. De um lado, os movimentos, sindicatos de profissionais da educação e acadêmicos, defendendo a gestão democrática da escola e, de outro, donos de escolas 
particulares, filantrópicas, comunitárias e confessionais, lutando pela centralidade das decisões e por privilégios na condução de seus estabelecimentos, sem a participação dos familiares.

Embora haja uma generalidade no âmbito das legislações quanto à gestão democrática, é importante destacar as inúmeras lutas dos movimentos sociais para que esta pauta de gestão democrática fosse contemplada na legislação, o que torna a sua concretização na educação brasileira uma conquista, porém parcial, uma vez que ainda está em pauta nos projetos progressistas e é indispensável pensar os espaços escolares da rede privada de ensino.

É possível reconhecer nos Conselhos Escolares o delineamento da necessária democracia no espaço da gestão escolar. Conforme Lück (2013a, p. 54), a democracia é entendida:

[...] como processo e não como ideário estabelecido a priori, aparece e se desenvolve incessantemente (re)construída, mediante o dinamismo específico da estrutura e funcionamento organizacional da comunidade escolar/educacional que se efetiva a partir das pessoas e do espírito humano da cultura organizacional da comunidade, mobilizando-os e sendo por estes elementos mobilizada.

Assim, com a finalidade de construir diretrizes voltadas ao fortalecimento dos Conselhos Escolares da Rede Municipal de Ensino de Santa Maria/RS, buscou-se fundamentos no conceito de gestão democrática

[...] como o processo em que se criam condições para que os membros de uma coletividade não apenas tomem parte, de forma regular e contínua, de suas decisões mais importantes, mas assumam responsabilidade por sua implementação. Isso porque democracia pressupõe muito mais do que tomar decisões: envolve a consciência de construção do conjunto da unidade social e de seu processo de melhoria contínua como um todo. (LÜCK, 2013a, p. $57)$.

Justamente, diretrizes para que a formação de Conselheiros Escolares, subsidiadas pela LDB $n^{\circ}$ 9.394/96 e pela Lei Municipal $n^{\circ} 4.740 / 2003$, possam considerar as demandas e as especificidades dos contextos escolares de Santa Maria/RS, bem como potencializar formação aos integrantes destes órgãos colegiados, já que não basta compor um Conselho Escolar e ter boa vontade em trabalhar compartilhadamente. É preciso, também, ter conhecimento e direcionamento no trabalho participativo.

Como resultado dos embates e debates, reafirma-se, na LDB/1996, o princípio da gestão democrática, colocando para os sistemas a sua definição. Entre avanços e recuos, as propostas de democratização da gestão da escola, no sentido de combater relações 
autoritárias, procuraram refletir-se no direito à participação da população na tomada de decisões, nas relações pautadas pelo diálogo, na aprendizagem da participação política. Passado o afã do texto legal, deparamo-nos com o contexto real da gestão democrática escolar, em grande maioria autoritária, hierarquizada e centralizadora, em que a participação da comunidade, nas tomadas de decisões, continua se constituindo como um desafio a ser transposto.

Nesse sentido, a defesa da gestão democrática, tomada aqui como sinônimo da administração em seu caráter emancipatório, dialógico, descentralizado, participativo e transformador, vislumbra possibilidades de superação da centralização do poder e hierarquização das decisões nos contextos educativos. Isso porque:

\begin{abstract}
Nas sociedades de classes, em que o poder está confinado nas mãos de uma minoria, a administração tem servido historicamente como instrumento nas mãos da classe dominante para manter o status quo e perpetuar ou prolongar ao máximo seu domínio. O que não significa que ela não possa vir a concorrer para a transformação social em favor dos interesses das classes subalternas desde que suas potencialidades sejam aproveitadas na articulação com esses interesses. Para isso, entretanto, é necessário que a atividade administrativa seja elevada de seu caráter espontaneamente progressista para uma práxis reflexivamente revolucionária (PARO, 2001, p. 32-33).
\end{abstract}

A luta pela democratização da escola tem trazido novos desafios para o poder público, entre eles a necessidade de se traçarem propostas de formação política para qualificar a participação da comunidade nos processos decisórios da escola. Nesse sentido, a luta parece não ter encerrado com a criação dos espaços institucionalizados de participação, como o conselho. Reconhecidamente, visto pela comunidade educativa como grande avanço, esse espaço de participação política, desde a sua criação até os dias de hoje, impõe dificuldades de atuação compartilhada com os demais setores da escola.

A própria forma de composição do conselho escolar revela uma tendência asselvajada, pois são muito aqueles que, mais próximos dos espaços de deliberação da escola, possuem informações privilegiadas, no que se refere ao poder de manipulação das exigências burocráticas do sistema de ensino. São grupos de professores, da direção da escola e dos funcionários, que se associam, isolando a participação daqueles que não têm fácil acesso às informações e conhecimentos - geralmente familiares e alunos.

Pautados pela exigência de formalidade que, segundo eles, garante o funcionamento das reuniões, esses grupos endossam a concepção tradicional de educação, hierarquizada e verticalizada, em grande medida orientada pela direção e pelo corpo docente, para garantir em 
suas mãos uma dinâmica do colegiado e o controle das ações, bem nos termos desejados pelo mestre explicador ${ }^{4}$.

Ao partir do que os membros não sabem, esse órgão colegiado atua sem equidade, com a lógica da desigualdade de inteligências e de condições destes para sua existência. Mas, paradoxalmente, procura no discurso formal nivelar as condições de seus participantes, não considerando a especificidade de cada contexto escolar e sua comunidade ali presente.

Diante das dificuldades de manifestar voz, a comunidade segue as condutas e expectativas já traçadas pelos segmentos escolares. Nessa perspectiva, a elaboração de diretrizes para a formação e atuação qualificada e comprometida com a superação desse estado de coisas não pode se furtar em incentivar, fomentar, acompanhar o cumprimento da garantia de direitos legalmente constituídos, assim como investir em processos formativos formais e não formais pode e deve ser uma possibilidade.

Para isso é que se tornam importantes ações de fortalecimento do CE, entre elas a formação qualificada dos conselheiros e conselheiras escolares no que tange a esclarecer a complexidade das atribuições deste órgão colegiado, em que cada membro possa construir um razoável conhecimento de sua estrutura e funcionamento não apenas da escola, mas, também, da rede e do sistema de ensino de que esta instituição educativa é partícipe. No entanto, não basta um conhecimento mecânico, decorado, acumulado quantitativamente e descontextualizado, sem proceder à sua análise. Para que os $\mathrm{CE}$ avancem na perspectiva da gestão democrática, é preciso considerar formas de atuação desse órgão colegiado (Figura 2):

Figura 2 - Atuação dos conselhos escolares
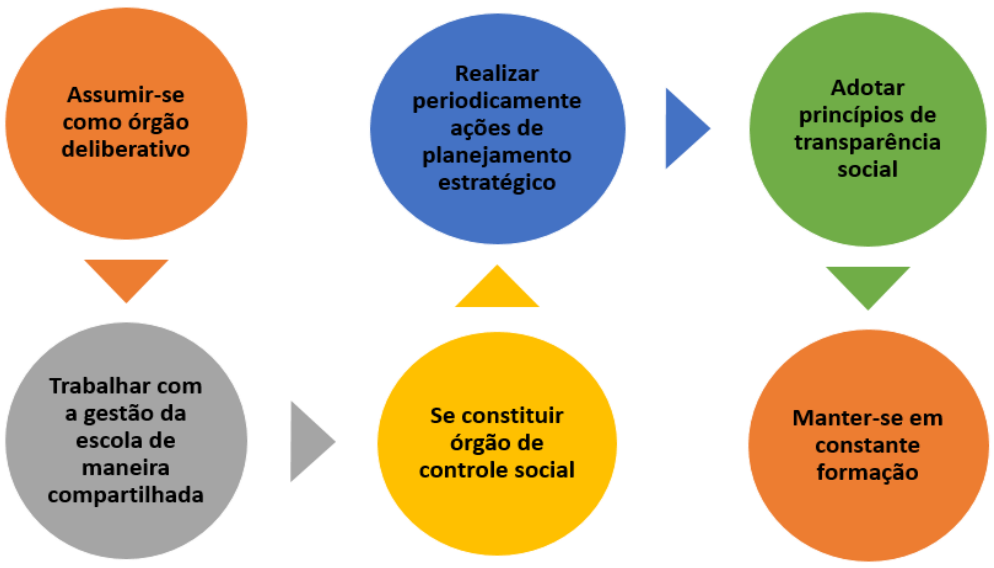

Fonte: Elaborada pela autora.

${ }^{4}$ Termo cunhado por Jacques Rancière, em O mestre ignorante. Nessa obra, Rancière (2005) se refere ao mesmo explicador como aquele que, ao ser o detentor da palavra, da explicação, transmite para o outro a sua interpretação impedindo-o de desenvolver sua própria interpretação, atuando como transmissor do conhecimento sem atuar como mediador na construção do conhecimento pelo outro (RANCIÈRE, 2005, p. 23). 
A atuação qualificada requer formação e é nessa lógica que na Matriz a seguir encontram-se Diretrizes para a Formação de Conselheiros Escolares (Figura 3):

Figura 3 - Matriz das diretrizes para a formação de conselheiros escolares da Rede Municipal de Ensino de Santa Maria/RS

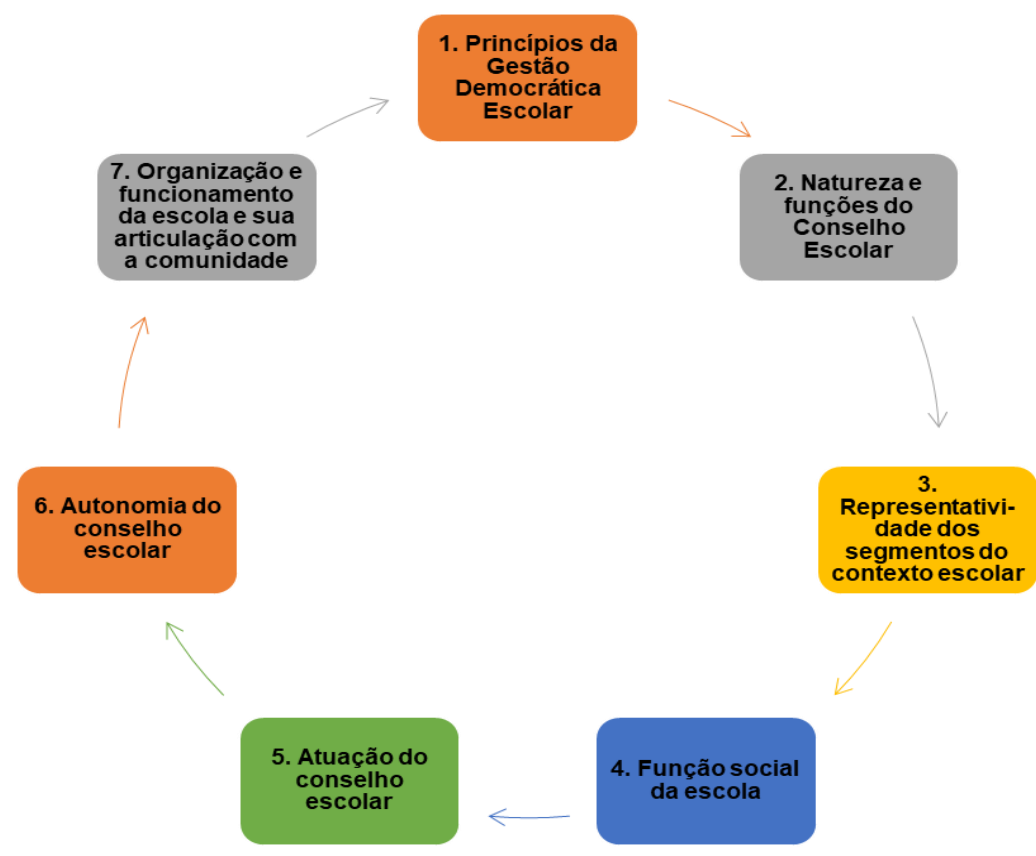

Fonte: Elaborada pela autora.

Considerando a Matriz das Diretrizes para formação de conselheiros escolares, explicita-se seus principais elementos fundantes:

1. Reconhecimento dos princípios de Gestão Democrática no funcionamento da escola, para compreender e otimizar participativamente e com autonomia os processos de tomada de decisões, planejamento, execução, acompanhamento e avaliação das dimensões administrativa, pedagógica e financeira no contexto escolar;

2. A compreensão da natureza e funções do Conselho Escolar como um órgão colegiado deliberativo, consultivo e fiscalizador, não tendo caráter políticopartidário, religioso, racial e nem de fins lucrativos;

3. O investimento na representatividade dos segmentos do contexto escolar, na perspectiva de promover a articulação entre os vários segmentos da comunidade escolar e os setores da escola, constituindo-se o CE no órgão máximo de direção e decisão na comunidade escolar, considerando o conjunto constituído pelos membros do magistério, alunos, pais ou responsáveis pelos alunos e funcionários que protagonizam a ação educativa da escola; 
4. Compreensão da atuação e representação de qualquer dos integrantes do conselho escolar com vistas ao interesse maior dos alunos, inspirados nas finalidades e objetivos da educação pública, para assegurar o cumprimento da função social da escola;

5. A ação do conselho escolar articulada com a ação dos profissionais que atuam na escola, preservada a especificidade de cada área de atuação;

6. Fundamentação da autonomia do conselho escolar com base nos seguintes compromissos: da legislação em vigor; da democratização da gestão escolar; das oportunidades de acesso, permanência e qualidade de ensino na escola pública de todos/as que a ela tem direito;

7. Compreensão de que o conselho escolar encaminhará ações que visem ao estabelecimento de diretrizes para organização e funcionamento da escola e sua articulação com a comunidade, responsabilizando-se pelas suas deliberações, visando ao coletivo e a qualidade de ensino, evitando-se o trato de interesse individuais.

Destaca-se que tais diretrizes de formação requerem ter por prioridade as demandas e especificidades de cada contexto escolar e, também, as levantadas junto às Redes e Sistemas de Ensino. Neste caso o município em estudo foi o de Santa Maria/RS, quando desta emergiu a falta de conhecimentos basilares como os princípios da gestão democrática e, principalmente, a função e atuação do conselho escolar como o principal mecanismo de democratização.

\section{Guisa conclusiva}

No exercício do poder está a essência da democracia. E a qualidade do exercício do poder está referida ao espaço de autonomia que fundamenta o ser cidadão e a finalidade da instituição educacional. O poder é exercido por todos os atores sociais em todas as ramificações da estrutura organizacional. Na dialética do funcionamento da sociedade e das organizações, todos exercemos estrategicamente nosso poder, jogamos nosso jogo, usamos nossas cartas. Jogo que pode ser jogado na perspectiva individualista - do ganhar algo de alguém - ou na perspectiva de um projeto coletivo de vida - do vencer com o outro.

Talvez essa seja a grande marca da burocracia: o exagero da papelada. Isso decorre da crença de que, depois de registrado no papel, tudo pode ser comprovado, testemunhado, como se a escrita materializasse o momento vivido, o que é, de certa forma, uma ilusão. A gestão escolar formalista também comete esse equívoco! As inúmeras atas de reuniões, o excesso de relatórios e composições processuais, no final, acabam virando "letra morta" e parando no fatídico "arquivo morto". Quando não se têm objetivos claros de reflexão da ação pedagógica, os registros perdem seu significado, tais como os planejamentos anuais, atas de 
conselho de classe e reuniões pedagógicas que nunca são revisitados, tornando-se, como dizia Paulo Freire, "palavra oca".

É natural da condição humana se prender ao que é conhecido, seguro, rotineiro. As transformações causam medo, insegurança, por isso são rechaçadas. A gestão escolar burocrática perdura a mudanças para perder seu status quo. Como toda instituição secular, a escola também resiste às mudanças, mesmo vendo suas estruturas clássicas se desfazerem como castelos de areia. Os currículos fragmentados, os regimentos anacrônicos, as metodologias manufatureiras são algumas das tantas renitências às mudanças que são necessárias à escola atual. Foi preciso repensar urgentemente os papéis dos atores no processo democrático, principalmente no âmbito da escola, a começar pelo fundamento do processo representativo.

Como instituição que deve preparar para a vida democrática, a escola precisa, antes de tudo, criar, no seu interior, processos decisórios coletivos, a fim de que os problemas possam aflorar e ser discutidos, pois os conflitos de visões de mundo, de ideias, de saberes e de interesses são próprios da vivência democrática. Caso o conflito não aflore, tem-se uma falsa harmonia e as contradições eclodem em um nível indesejável, que é o pessoal, e não em uma esfera institucional.

$\mathrm{Na}$ tentativa de cultivar esse processo democrático nas escolas, a Lei de Diretrizes e Bases da Educação Nacional, Lei nº 9.394/96, institucionalizou os conselhos escolares, cujas funções são limitar o despotismo de alguns gestores, responsabilizar cada segmento da comunidade escolar e implantar um modelo de gestão colegiada, infelizmente ainda tão raro nas instituições educativas brasileiras. Mas os gestores não precisam ter medo do conselho escolar, pois permanecem como figuras importantes e necessárias na mediação e articulação dos segmentos escolares, fortalecendo-os e acompanhando muito de perto suas contribuições e responsabilidades. Pois, trazer ao coletivo a responsabilidade para com o desenvolvimento da escola, pode fazer com que muitos dos obstáculos sejam superados, principalmente porque faz do dirigente escolar alguém que realiza mediações junto a uma equipe responsável pelo caminhar progressivo da escola, bem diferente de uma figura que concentra em suas mãos os poderes de responsabilidade e decisão da mesma.

Com o CE, tem-se uma nova concepção de gestão escolar, pautada na coletividade, o que implica a admissão de um modelo gestionário pensado a partir do conflito, devido aos interesses diversos dos segmentos que compõem a instância máxima de deliberação escolar. Dessa forma, a ideia de conflito sempre foi reducionista na sociedade brasileira, devido à tradição liberal-consensual que marcou a história de nossas instituições. Neste caso, o conflito 
é tido como algo não grato; no entanto, a contradição é inerente à sociedade, mesmo nos microrrelacionamentos. É próprio da compreensão dialética do mundo conceber o conflito enquanto método e, a partir dele, vislumbrar a superação, a elevação de nível, tanto das atitudes quanto das consciências.

Como sabemos, as escolas são instituições eminentemente conflituosas, e é aí que o conselho escolar se apresenta como mecanismo de democratização importante, pois se trata de um órgão colegiado que fomenta a explicitação dos desejos, objetivos, ansiedades e sonhos dos diversos segmentos. Sendo assim, com certeza, os alunos farão reivindicações e elaborarão propostas diversas das dos professores, da dos pais e vice-versa. Abre-se, então, a possibilidade do diálogo, do confronto, da discussão e, no final, todos têm direito ao voto e à defesa de seu ponto de vista. Consolida-se, nessa lógica, uma vivência democrática, na qual se aprende a falar, mas, principalmente, a ouvir o outro e encará-lo como sujeito de direitos.

A melhor forma de promover a conscientização é a vivência. Há muito tempo, o discurso pedagógico prima pela democratização da escola, mas o verbalismo não foi superado porque está entranhado na inteligência brasileira um misto de acomodação com a hierarquização do poder e da falta de hábitos democráticos nas relações domésticas e públicas.

Então, é preciso vivenciar, desde a escola, os mecanismos de participação popular, que precisam ir além do voto, do sufrágio para os dirigentes, saltando ao patamar das decisões colegiadas. É muito comum ao brasileiro confundir democracia com o ato de votar, achando que sua participação começa e acaba aí, e delegando aos representantes todo o arbítrio sobre as questões sociais. Esse pensamento poderá ser emancipado com o estabelecimento de um modelo diferente, que pode ser facultado via escola e respectivos mecanismos de participação na gestão compartilhada e coletiva.

Mudar esse quadro depende, em muito, de atuações e do empenho dos responsáveis pelas políticas educacionais, mas também depende das ações e empenho conjunto deste órgão colegiado - o conselho escolar. Nesse sentido, faz-se necessária a busca por melhorias que sejam capazes de garantir aos conselheiros escolares uma atuação qualificada. A proposta de reuniões formativas para conselhos escolares pode constituir-se uma estratégia importante e, em tese, relativamente simples de ser implementada, uma vez que o espaço democrático está normatizado pelas políticas públicas, e precisa, de fato, constituir-se no âmbito escolar para além das ações e reuniões protocolares e burocráticas. Requer ser incorporado à rotina dos conselheiros, a fim deste órgão colegiado ter acesso à estrutura da escola no exercício do direito à participação, além de divulgar informações, participar ativamente da elaboração de 
projetos, planos e propostas, solicitar espaço na escola para discutir com seus pares, fazer levantamento de dados, o que exige acesso a informações e formação para interpretá-las, bem como sugerir, discutir, contribuir com propostas num posicionamento em prol do coletivo.

$\mathrm{Na}$ pesquisa, ficou evidente que o conselho escolar tem um papel importante no enfrentamento desse complexo problema - "tornar o espaço escolar efetivamente democrático". Assim, afirmamos que

- muitas concepções estão em disputa relativamente às vivências em termos de gestão, autonomia na escola, mas, se quisermos uma gestão que favoreça um clima de cooperação e compromisso social, ela não pode ser autoritária e centralizadora;

- a participação da comunidade na gestão escolar torna-se de fundamental importância para a definição das políticas educativas mais amplas, com metas que incluem os sujeitos de direito;

- a gestão descentralizada e os projetos democráticos, autônomos e inovadores ajudam a fortalecer a identidade da escola e consolidam laços democráticos e de coletividades, criando um clima de ampliação da cidadania, fortalecendo a atuação dos conselhos escolares;

- $\quad$ as relações entre gestão democrática da escola e gestão democrática dos sistemas necessitam constituir-se uma prioridade na sociedade, haja vista a sua configuração - de sociedade tecnológica, em rede e democrática.

O compromisso da escola se ampliou pelo Art. 206 da Constituição Federal, inciso VI, que atribui “[...] a gestão democrática do ensino público, na forma da lei” (BRASIL, 1988). Os novos modelos de gestão do ensino público implicaram formas descentralizadas de administração e recursos, bem como novos repasses de obrigações para a escola, refletida em forma da lei nas constituições estaduais e leis municipais. Portanto, a descentralização e a autonomia correspondem a processos de democratização que tem como centralidade a prática democrática.

Se a participação requer compromisso com o projeto educacional coletivo, o compromisso advém dessa identificação, desse sentimento de pertença. As pessoas se comprometem com aquilo em que acreditam, com aquilo que lhes diz respeito, que faz sentido para suas vidas. Se é assim, então, passam a querer exercer seu poder, participar das decisões, porque adquiriram a consciência de que estas ações afetam suas vidas.

\section{REFERÊNCIAS}

BOBBIO. N. A era dos direitos. Nova ed. Rio de Janeiro: Elsevier, 2004.

FLICK, U. Desenho da pesquisa qualitativa. Porto Alegre: Artmed, 2009. 
HORIKAWA, A. Y. Pesquisa Colaborativa: uma construção compartilhada de instrumentos. Revista Intercâmbio, São Paulo, v. 18, p. 22-42, 2008.

IBIAPINA, I. M. L. Pesquisa Colaborativa: investigação, formação e produção de conhecimentos. Brasília: Líber Livro Editora. 2008.

LÜCK, H. A gestão participativa na escola. 11.ed. Petrópolis, RJ: Vozes, 2013 a.

LÜCK, H. Concepções e processos democráticos de gestão educacional. 9. ed. Petrópolis, RJ: Vozes, 2013 b.

LUNA, S. V. de. Planejamento de pesquisa: uma introdução. São Paulo: EDUC, 2002.

MOROZ, M. GIANFALDONI, M. H. T. A. O processo de pesquisa: iniciação. 2. ed. Brasília: Líber Livro, 2006.

MULLER, P.; SUREL, Y. Análise das políticas públicas. Pelotas, EDUCAT, 2002.

PARO, V. H. Administração escolar: introdução crítica. 10 ed. São Paulo: Cortez, 2001.

\section{Como referenciar este artigo}

DALLA CORTE, Marilene Gabriel; MACHADO, Cristina Magalhães Foletto. Fortalecimento dos conselhos escolares no cenário da gestão democrática da rede municipal de ensino de Santa Maria - RS. Revista Ibero-Americana de Estudos em Educação, Araraquara, v. 15, n. 2, p. 522-538, abr./jun. 2020. e-ISSN: 1982-5587. DOI: https://doi.org/10.21723/riaee.v15i2.12093

Submetido em: 21/01/2019

Revisões requeridas: 30/04/2019

Aprovado em: 28/06/2019

Publicado em: 20/02/2020 